Review

\title{
Hydrogen as a New Class of Radioprotective Agent
}

\author{
Liren Qian $^{1 \bowtie}$, Jianliang Shen ${ }^{1 凶}$, Yunhai Chuai ${ }^{3}$, Jianming Cai ${ }^{2}$ \\ 1. Department of Haematology, Navy General Hospital, Fucheng Road, Beijing, PR China \\ 2. Department of Radiation Medicine, Faculty of Naval Medicine, 2nd Military Medical University, Shanghai, PR China \\ 3. Department of Obstetrics and Gynecology, Navy General Hospital, Fucheng Road, Beijing, PR China.
}

\begin{abstract}
$\triangle$ Corresponding author: Liren Qian and Jianliang Shen, Department of Haematology, Navy General Hospital, Fucheng Road, Beijing, 100048, P.R. China, e-mail: qlr2007@126.com (Liren Qian) and shenjianliang@csco.org.cn (Jianliang Shen).
\end{abstract}

(c) Ivyspring International Publisher. This is an open-access article distributed under the terms of the Creative Commons License (http://creativecommons.org/ licenses/by-nc-nd/3.0/). Reproduction is permitted for personal, noncommercial use, provided that the article is in whole, unmodified, and properly cited.

Received: 2013.07.21; Accepted: 2013.08.24; Published: 2013.09.14

\begin{abstract}
It is well known that most of the ionizing radiation-induced damage is caused by hydroxyl radicals $(\cdot \mathrm{OH})$ follows radiolysis of $\mathrm{H} 2 \mathrm{O}$. Molecular hydrogen $(\mathrm{H} 2)$ has antioxidant activities by selectively reducing $\cdot \mathrm{OH}$ and peroxynitrite(ONOO-). We firstly hypothesized and demonstrated the radioprotective effect of $\mathrm{H} 2$ in vitro and in vivo, which was also repeated on different experimental animal models by different departments. A randomized, placebo-controlled study showed that consumption of hydrogen-rich water reduces the biological reaction to radiation-induced oxidative stress without compromising anti-tumor effects. These encouraging results suggested that $\mathrm{H} 2$ represents a potentially novel preventative strategy for radiation-induced oxidative injuries. $\mathrm{H} 2$ is explosive. Therefore, administration of hydrogen-rich solution (physiological saline/pure water/other solutions saturated with $\mathrm{H} 2$ ) may be more practical in daily life and more suitable for daily consumption. This review focuses on major scientific and clinical advances of hydrogen-rich solution/ $\mathrm{H} 2$ as a new class of radioprotective agent.
\end{abstract}

Key words: Hydrogen; free radical; radiation; radioprotection.

\section{Introduction}

Great benefits for people have been got because of extensive utilization of atom energy in many fields such as medicine, civil industry, agriculture, military etc. In the meantime, how to protect human health and safety from severe nuclear radiation was always a critical problem in the world [1]. It is a novel scientific topic for radiologists to look for high-effective radiation protectants with low toxicity. In fact, exploitation the ideal radiation protectants has always been emphasized in the field of radiation [2, 3]. However, it is always an obstacle. As we know, damaging effects of radiation are divided into direct effect and indirect effect, which accounts for about most of the damages [4]. Since the indirect effect mainly due to the abundant free radicals caused from radiation, so blocking and scavenging of free radicals become our most important protecting strategy. In 2007, Ohsawa et al. [5] found that molecular hydrogen could selectively reduce cytotoxic reactive oxygen species in vitro and exert therapeutic antioxidant activity. From then on, research on hydrogen set off a worldwide upsurge [6-10]. Hydrogen could selectively reduce hydroxyl radicals excited our interest, because most of irradiation induced injury was caused by hydroxyl radicals. Therefore, we firstly reasoned and demonstrated that hydrogen might have great radioprotective effects in $2010[11,12]$. Since then, application of hydrogen on radioprotection was well investigated [13-17]. It was also then used in clinic to improve the quality of life of patients treated with radiotherapy for liver tumours [18]. The objective of this review was to offer an overview of major scientific and clinical advances of hydrogen as a new class of radioprotective agent.

\section{Detrimental biological effects of radia- tion}

The detrimental biological effects of radiation are divided into direct effect and indirect effect. In phys- 
ics, radiation is a process in which energetic particles travel through a medium or space. Direct detrimental biological effect of radiation is caused by radiation energy in the exposure pathway, which targets molecules including DNA, proteins and lipids, et al [14]. Direct effect could be prevented by radiation shielding materials. However, indirect detrimental biological effect of radiation is caused by free radicals generated from radiolysis of $\mathrm{H} 2 \mathrm{O}$ (Figure 1). Among those free radicals generated from radiolysis of $\mathrm{H} 2 \mathrm{O}$, hydroxyl radical is the most reactive product. Detrimental effects of IR on biological tissues are, in major part, mediated via increased production of hydroxyl radicals. It was estimated that $60-70 \%$ of the IR-induced cellular damage was caused by hydroxyl radicals [4]. Hydroxyl radicals produced during radiolysis of water can trigger oxidation of DNA, lipids, amino acids, saccharides etc leading to formation of various secondary free radicals. These free radicals can produce severe health impairments due to injury and failure to susceptible cells and organs[19, 20]. DNA is one of the major targets of free radicals and 8-OHdG is formed from deoxyguanosine in DNA by hydroxyl radicals [21], which is also a biomarker of carcinogenesis [22]. Membrane lipids are also one of the major targets of free radicals [23]. Lipid peroxidation products including malondialdehyde, TBARs, etc are the indices of lipid damage [24], leading to changes in membrane permeability $[25,26]$. Structure of proteins could also be changed by hydroxyl radical and other free radicals, which induced the change in the function of proteins [27].

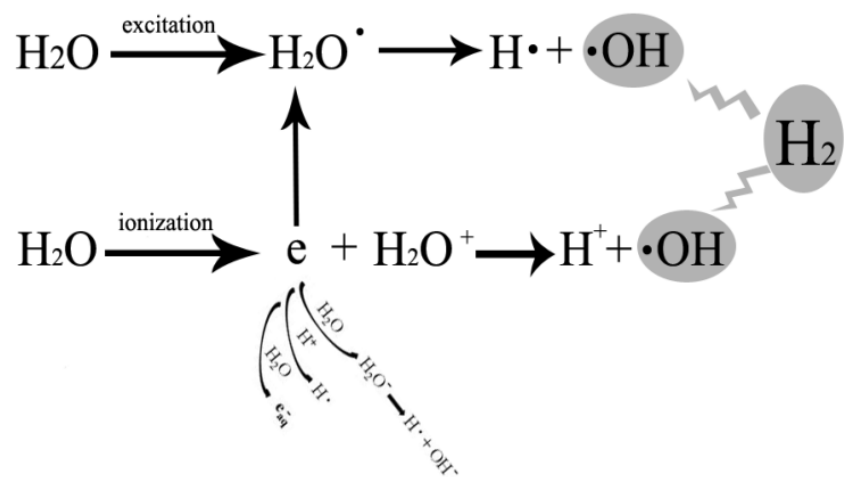

Figure I. Free radicals generated during radiolysis of water and cytotoxic oxygen radicals that hydrogen could selectively reduce. Initial radiation chemistry of ionization and excitation is to generate $\mathrm{H}_{2} \mathrm{O}^{+}$and $\mathrm{e}^{-}$from the ionization of $\mathrm{H} 2 \mathrm{O}$, and hydrogen atom $(\mathrm{H} \bullet)$ and hydroxyl radical $(\bullet \mathrm{OH})$ from the excited $\mathrm{H} 2 \mathrm{O}$. $\bullet \mathrm{OH}$ is the cytotoxic oxygen radical that hydrogen could selectively reduce which caused most of the IR-induced cellular damage.

\section{Hydrogen}

Hydrogen is the lightest and most abundant chemical element. Molecular hydrogen is a colorless, odorless, nonmetallic, tasteless, highly flammable diatomic gas which was firstly documented by Philippus Aureolus Paracelsus in 1520 as a kind of flammable gas [28]. It was named by Lavoisier in 1783 by a french word" hydrogene" [28]. However, hydrogen was extensively used in aeronautical nature such as hydrogen balloon and in chemical field such as fuel processing, fertilizer production $((3 \mathrm{H} 2+\mathrm{N} 2 \rightarrow$ $2 \mathrm{NH} 3$ ), etc since 1783 while it was seldom used in medicine. Early in 1888, Pilcher JE et al. reported one of the very publications linking hydrogen and medicine. They reported that hydrogen gas was insufflated the gastro-intestinal canal to locate visceral injuries, avoiding unwarranted surgeries [29]. This paper is probably the first document linking hydrogen and medicine. Until 1975, Dole et al. [30] reported that hyperbaric hydrogen may be a possible treatment for cancer. They found a marked regression of the skin squamous cell carcinoma by inhalation of a mixture $(2.5 \% \mathrm{O} 2$ and $97.5 \% \mathrm{H} 2)$ at a total of $0.8 \mathrm{MPa}$ for 2 weeks in a mouse model. They tried to elucidate the phenomenon with the possibility of $\mathrm{H} 2$ as a free radical decay catalyser. In 1988, H2 was demonstrated reducing hydroxyl radicals produced by radiolysis or photolysis of $\mathrm{H} 2 \mathrm{O}$ in cell free systems by Buxton et al [31]. In 2001, Gharib B et al. reported that H2 attenuated schistosomiasis-associated chronic liver inflammation in mice [32]. However, these investigations did not draw attention from researchers. Until 2007, Ohsawa et al. [5] discovered that hydrogen gas has antioxidant and antiapoptotic properties that protect the brain against ischemia-reperfusion injury and stroke by selectively neutralizing hydroxyl and peroxynitrite radicals. This study was well designed and took hydrogen gas into a new era. It has been demonstrated that $\mathrm{H} 2$ exerted preventive or therapeutic effects on cerebral, myocardial, hepatic ischemia-reperfusion injuries, intestinal transplantation, lung transplantation, renal transplantation, heart transplantation, acute graft-versus-host disease post allogeneic hematopoietic stem cell transplantation, etc $[33,34]$. Recent basic and clinical research revealed that hydrogen is an important physiological regulatory factor with antioxidant, anti-inflammatory and anti-apoptotic protective effects on cells and organs [35-40]. Hydrogen was also demonstrated has radioprotective effects on cultured cells and mice [11-16, 41] (Figure 2). $\mathrm{H}_{2}$ exert antioxidative effects with few toxic side effects. Saitoh et al. detected mutagenicity, genotoxicity and subchronic oral toxicity of hydrogen in a rat model [42]. In the model they observed sig- 
nificant changes of basophil ratio of blood in female rats and decreased aspartate aminotransferase and alanine aminotransferase in male rats. However, these changes were not considered biologically significant. In another study on human beings, Nakao A et al. also observed similar clinical chemistry parameters [9].

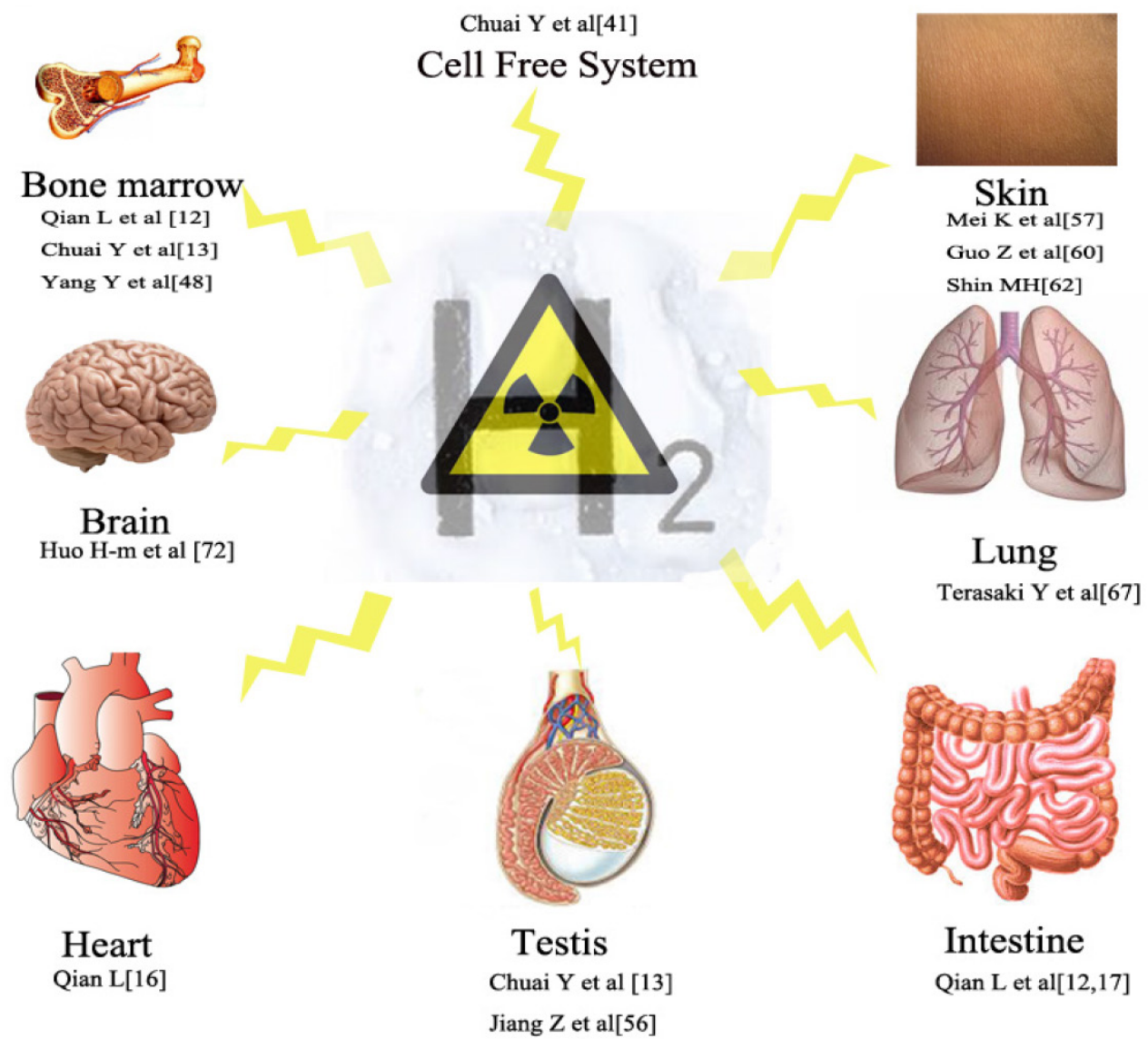

Figure 2. Radioprotective effects of hydrogen on different systems including cell free system, intestine, haematopoietic system, testis, skin, Lung, cardiovascular, brain, etc.

\section{Radioprotective effects of hydrogen Cell free system}

In cell free systems, our group produced $\cdot \mathrm{OH}$ by radiolysis of $\mathrm{H}_{2} \mathrm{O}$ and Fenton reaction [41]. In the study, we found that $71.2 \%$ of $\mathrm{OH}$ in the Fenton reaction was reduced by $\mathrm{H} 2$ dissolved in phosphate buffer $(10 \mathrm{mM})$ solution at $23{ }^{\circ} \mathrm{C}$ and $\mathrm{pH} 7.4$ under 0.4 $\mathrm{MPa}$ for 2 hour, while $88.7 \%$ of $\mathrm{OH}$ was reduced in radiolysis of $\mathrm{H}_{2} \mathrm{O}$ by $5 \mathrm{~Gy}{ }^{60} \mathrm{Co} \gamma$-ray. When $\mathrm{H} 2$ was replaced with nitrogen $\left(\mathrm{N}_{2}\right)$, the levels of $\mathrm{OH}$ did show significant change.

\section{Intestine}

The gastrointestinal tract is one of the most susceptible organs to radiation [43]. As low as 1 Gy of radiation induces dramatic increase in apoptosis in mouse small intestinal crypt within three to six hours after exposure, predominantly in the stem cell region [44] . To study the radioprotective effects of $\mathrm{H} 2$ on intestine, we chose Human intestinal crypt HIEC cells to study which was sensitive to irradiation $[12,17]$. In the study, cells were treated with or without different concentrations (0.1-0.4 mmol/L) of $\mathrm{H} 2$ before exposed to different doses ofy-radiation (up to $8 \mathrm{~Gy}$ ). We demonstrated that treating cells with hydrogen before irradiation could significantly inhibit IR-induced cell apoptosis, increase viability of Human intestinal crypt HIEC cells. In 2010, our group also demonstrated that intraperitoneal injection of hydrogen-rich saline before radiation in a mouse model protected the gastrointestinal endothelia from radiation-induced injury, decreased plasma MDA and intestinal 8-hydroxydeoxyguanosine levels and protected plasma levels of endogenous antioxidant enzymes including superoxide dismutase and glutathione-S-transferase [12].

\section{Haematopoietic system}

The haematopoietic system has a high level of cells turnover which is also one of the most sensitive system to IR [45]. Myelosuppression is a critical issue 
for individuals exposed to IR which always treated by hematopoietic transplantation but with low efficacy $[46,47]$.The primary cause of radiation death in sublethal dose range is due to sepsis, resulting from low numbers in bone marrow cells and leukocytes of peripheral blood. To study the radioprotective effects of $\mathrm{H} 2$ on haematopoietic system, we chose Human Lymphocyte AHH-1 cells to study which were sensitive to irradiation [12]. In the study, cells were treated with or without different concentrations (0.1-0.4 $\mathrm{mmol} / \mathrm{L}$ ) of $\mathrm{H} 2$ before exposed to different doses of $\gamma$-radiation (up to $8 \mathrm{~Gy}$ ). We demonstrated that treating cells with hydrogen before irradiation could significantly inhibit IR-induced cell apoptosis, increase viability of Human Lymphocyte AHH-1 cells. Endogenous antioxidants (superoxide, glutathione) were protected by hydrogen, while malondialdehyde and 8-hydroxydeoxyguanosine concentrations of Human Lymphocyte AHH-1 cells were decreased. Those results showed that the protective effects of hydrogen had positive correlation with the concentrations of hydrogen. However, if we treated cells after radiation, the therapeutic effects of $\mathrm{H} 2$ was not significant [12].

In a study by Chuai $\mathrm{Y}$ et al, hydrogen-rich saline prior to IR increased bone marrow nucleated cells (BMNCs) and leukocyte counts in irradiated mice compared with those without hydrogen. In the study, Hydrogen -rich saline prior to IR also increased the levels of spleen weights, endogenous haematopoietic spleen colony formations (endoCFUs) [13].

In another study by Yang $Y$ et al., they demonstrated $\mathrm{H} 2$ reduced ROS level in Human lymphocyte AHH-1 cells as well as in the radiolysis of water induced by $12 \mathrm{C} 6+$ heavy ion radiation.[48] They also showed $\mathrm{H} 2$ attenuated cell apoptosis and inhibited Caspase 3 activation induced by $12 \mathrm{C} 6+$ heavy ion radiation-induced.

\section{Testis}

Testis is an important organ of the male reproductive system, which is especially sensitive to ionizing radiation (IR) because of the presence of rapidly proliferating cells (spermatogonia)[49]. Doses as low as 0.1 Gy are known to cause damage to spermatogonia $[41,49]$.

Biochemical and morphological injury can be caused by irradiation in testicular tissue[50-53]. Only $2 \%$ of men who received total-body IR are able to father children later in life[54]. In 2012, Chuai Y et al. reported the radioprotective effect of $\mathrm{H} 2$ on male germ cells by ameliorating apoptotic cells in testicular tissue, and by preserving viability of stem spermatogonia, daily sperm production and sperm quality. In the study, WR-2721 was used as a reference compound, which is the only radioprotectant approved by
FDA [55]. Inspiringly, although the radioprotective effects of $\mathrm{H} 2$ have been shown to be less than WR-2721, the exceeded protective effect of WR-2721 seems not to be prominent. In accordance with these results, in later papers by Chuai $Y$ et al and by Jiang $Z$ et al, they also demonstrated the radioprotective effects of hydrogen on testis [13, 56] by protecting seminiferous epithelium, preserving testis weight, testis dimensions, sperm count, sperm motility from IR. However, in the paper by Jiang $\mathrm{Z}$ et al, it was found that the radioprotective effect of hydrogen on testis is similar to WR-2721 at one time point (after a 4-day initiation of irradiation) which is better than the results by our group.

\section{Skin}

Skin is a biological defense barrier of human body. Radiation injuries skin directly by radiation energy or indirectly by free radicals, causing radiodermatitis which occurred in nearly $95 \%$ of patients receiving radiation therapy [57]. There are generally two types of radiodermatitis: acute radiodermatitis(usually occur within 90 days), chronic radiodermatitis (may occurred over a prolonged period) which often exhibited by the onset of erythema, swelling, blisters, and ulceration, followed by development of chronic inflammation, necrosis, fibrosis, and lymphedema[58, 59]. In 2012, Guo Z et al.[60] firstly reported that hydrogen-rich saline protected against UVB radiation injury, possibly by reducing inflammation and oxidative stress. They demonstrated that hydrogen-rich saline had protective effects by altering the levels of markers including necrosis factor alpha, interleukin (IL)-1 $\beta$, IL-6, tissue superoxide dismutase, malondialdehyde and nitric oxide activity and relieved morphological skin injury against UVB radiation injury on C57BL/ 6 rats. In 2013, Mei K et al.[57] reported the protective effects of hydrogen on skin in vitro and vitro against $\gamma$ ray. In the study, our group found hydrogen significantly reduced the severity of dermatitis caused by radiation, accelerated tissue recovery, and reduced the extent of radiation-induced weight loss in rats after a single dose of 15 or 20 Gy radiation. We also found hydrogen protected rats from cumulative doses of 30 Gy delivered in three fractions. In the study, hydrogen also protected Immortalized human keratinocytes (HaCaT cells) from radiation-induced injury. In 2013, Rosa Mistica Ignacio et al. [61] demonstrated the protective effect of hydrogen reduced water (HRW) on UVB-mediated skin injury in hairless mice by balneotherapy. In their study, bathing with HRW significantly reduced the levels of skin damage by decreasing the level of inflammatory cytokines including IL-1 $\beta$, IL-6, TNF- $\alpha$ and IFN- $\gamma$, as well as increased activity of glutathione 
peroxidase.

In their study, HRW bathing also protect UV-induced corneocytes damage and ultrastructural changes.

Interestingly, in a recent study by Mi Hee Shin et al.[62], they observed that $\mathrm{H}(\mathrm{H} 2 \mathrm{O})$ (atomic hydrogen surrounded by water molecules) application to human skin prevented UV-induced erythema and DNA damage. In their stuy, $\mathrm{H}(\mathrm{H} 2 \mathrm{O})$ significantly prevented UV-induced MMP-1, COX-2, IL-6 and IL-1 $\beta$ mRNA expressions in human skin in vivo. They also found that $\mathrm{H}(\mathrm{H} 2 \mathrm{O})$ prevented UV-induced ROS generation and inhibited UV-induced MMP-1, COX-2 and IL-6 expressions, and UV-induced JNK and c-Jun phosphorylation in HaCaT cells.

\section{Lung}

The lung is one of the organs most susceptible to radiation injury [63]. Radiation pneumonitis is an inflammation of the lungs that occurs when lung or whole body was irradiated. Development of interstitial pneumonitis increases according to radiation dose, especially single-fraction total body irradiation at higher dose rates [64] and higher total lung doses $[65,66]$. In 2011, our group hypothesized that hydrogen may be a possible prevention strategy of radiation pneumonitis [15]. In 2011, Terasaki et al. [67] showed that $\mathrm{H} 2$ reduced irradiation-induced $\mathrm{OH}$ levels in human lung epithelial cell line A549 cells. They demonstrated that pretreatment of $\mathrm{H} 2$ could reduce the fluorescence intensity of hydroxyphenyl fluorescein in irradiated A549 cells. They demonstrated pretreatment of $\mathrm{H} 2$ reduced the products of oxidative stress including 4-hydroxy-2-nonenal, 8-hydroxydeoxyguanosine, etc. H2 also could significantly reduce levels of apoptosis-associated proteins including Bax and active caspase 3 in irradiated A549 cells after a $24 \mathrm{~h}$ incubation with H2-rich solution. In vivo, they demonstrated that $\mathrm{H} 2$ treatment reduced oxidative stress and apoptosis, measures of acute damage in the lungs of mice within 1 week after whole thorax irradiation by immunohistochemistry and immunoblotting. In their study, $\mathrm{H} 2$ treatment reduced lung fibrosis by chest computed tomography, Ashcroft scores, and type III collagen deposition at 5 months after irradiation.

\section{Cardiovascular}

Irradiation of the heart can cause chronic impairment of cardiac pump function and cardiac disease [68]. The most significant type of radiation-induced heart disease (RIHD) appears to be that of myocardial damage, which may result from loss of alkaline phosphatase activity of capillary endothelial cells $6-10$ weeks after irradiation $[69,70]$. In addition to myocardial degeneration, perivascular and interstitial fibrosis are seen [71]. Injury of heart by irradiation has been shown to be caused by the hydroxyl radical. Intervention to protect the heart from the damage of the hydroxyl radical by hydrogen has been proposed, suggested, and performed by our group. We investigated the cardioprotective properties of hydrogen by pretreating mice with hydrogen rich water prior to irradiation. The results were pleasing in the study, $90 \%$ of the mice without hydrogen rich water pretreatment died, while $80 \%$ of the mice with hydrogen treatment lived after 30 days post-radiation. When focusing on the myocardium, hydrogen pre-treatment proved to have cardioprotective properties by decreasing melanodialdehyde (MDA) and eight-hydroxydeoxyguanosine (8-OHdG) levels as opposed to the non-treatment counterparts, which showed increased levels of those oxidative stress markers [16].

\section{Brain}

In a study by Huo H. et al. in Chinese [72], hydrogen was demonstrated alleviating oxidative stress and early-phase radiation-induced brain injury. They found that the brain water content and the contents of 8 -OHdG in the hydrogen group were lower than the control group at $7^{\text {th }}$ day and $14^{\text {th }}$ day post irradiation. The contents of SOD were significantly higher in the hydrogen group from $1^{\text {st }}$ to $7^{\text {th }}$ day post irradiation, while the contents of MDA were significantly lower in the hydrogen group from $1^{\text {st }}$ to $14^{\text {th }}$ day post irradiation. They also found the damage degree in the nerve cells of hippocampus was less in the hydrogen group.

\section{Lymphoma}

Ionizing radiation (IR) is also a well-known carcinogen for various human tissues and a complete carcinogen that is able to both initiate and promote tumor progression [73-75]. A study by Zhao L. et al. found that molecular hydrogen protects mice from radiation induced thymic lymphoma in BALB/c mice [76]. They found that radiation-induced thymic lymphoma rate in the hydrogen group was significantly lower than in the control group and hydrogen treatment significantly prolonged the latency of lymphoma development after the split dose irradiation by reducing ROS, which has been found to be a factor of inducing cancers.

\section{Radiotherapy}

Although a remarkable progress about the application of hydrogen as a radioprotectant has been made in past 6 years, there were only a few clinical data. Ki-Mun Kang et al. performed a randomised, placebo-controlled study on 49 patients receiving ra- 
diotherapy for malignant liver tumour. Hydrogen-rich water was produced by metallic magnesium $(\mathrm{Mg})\left[\mathrm{Mg}+2 \mathrm{H}_{2} \mathrm{O}=\mathrm{Mg}(\mathrm{OH}) 2+\mathrm{H} 2\right]$, and the final concentration of $\mathrm{H} 2$ reached to $0.55-0.65 \mathrm{mM}$. Results showed that daily consumption of hydrogen-rich water for 6 weeks reduced reactive oxygen metabolites in the blood and maintained blood oxidation potential of these patients. Quality of life (QOL) scored during radiotherapy were improved in patients with hydrogen-rich water compared to those with placebo. This study did not find differences in tumor response to radiotherapy as application of hydrogen-rich water [18].

\section{Future Directions}

The application of hydrogen on radioprotection has been widely studied. Some investigators even proposed application hydrogen therapy in space flight [77]. Definition of hydrogen as a kind of antioxidant seems cannot explain all radioprotective effects of hydrogen. But people have not found any other mechanism to replace the reduction of $\cdot \mathrm{OH}$ by $\mathrm{H} 2$ [41]. The exact mechanism and signaling pathway involved in the protection role of hydrogen in ionizing radiation injury need to be studied in the future. There were only a few researches explain molecular hydrogen exerted its effect not only as an antioxidant. Itoh et al. [78, 79] suggest that $\mathrm{H} 2$ may become a gaseous signalling molecule like nitric oxide (NO), carbon monoxide (CO) and hydrogen sulphide (H2S) for the first time. They showed that $\mathrm{H} 2$ suppressed FceRI-associated signal transduction and prevented degranulation of mast cell, but not through reducing the $\cdot \mathrm{OH}$, and they also demonstrated that $\mathrm{H} 2$ inhibited lipopolysaccharide/interferon $\gamma$ induced NO production through modulation of signal transduction in the macrophage. An assay of DNA microarrays in the livers detected 548 up-regulated and 695 down-regulated genes in rats after 4 weeks of drinking hydrogen-rich water, and those genes for oxidoreduction-related proteins were enriched in the up-regulated groups [80]. However, at present there is no direct evidence could confirm hydrogen gas is a new signalling molecule, which may need further investigations.

\section{Conclusion}

Researchers have always been hammering at looking for an ideal radioprotectant. The sulfhydryl compound amifostine, named WR-2721, which is the only radioprotectant registered for using in human, has shown good radioprotective effects [55]. But it has many side effects limiting its clinical use such as hypertension, nausea, vomiting, and other side effects [81]. Some nature antioxidants such as Vitamins,
Flavonoids, etc. have fewer toxic effects but also with lower radioprotection. Therefore, an ideal radioprotectant should be effective with few side effects. To date, no radioprotectant can fulfill the criteria. $\mathrm{H} 2$ as a new class of radioprotective agent may give us more hope, although there are still lots of future research needs to be done.

\section{Acknowledgments}

This work was supported by a grant from the National Natural Science Foundation of China (Grant No.81072241).

\section{Competing Interests}

The authors have declared that no competing interest exists.

\section{References}

1. Damron TA, Spadaro JA, Horton JA, Margulies BS, Strauss JA, Farnum CE. Novel radioprotectant drugs for sparing radiation-induced damage to the physis. Int J Radiat Biol. 2004; 80: 217-28.

2. Vijayalaxmi, Reiter RJ, Tan DX, Herman TS, Thomas CR, Jr. Melatonin as a radioprotective agent: a review. Int J Radiat Oncol Biol Phys. 2004; 59: 639-53. doi:10.1016/j.ijrobp.2004.02.006S0360301604002469 [pii].

3. Maisin JR. Bacq and Alexander Award lecture--chemical radioprotection: past, present, and future prospects. Int J Radiat Biol. 1998; 73: 443-50.

4. Ward JF. DNA damage produced by ionizing radiation in mammalian cells: identities, mechanisms of formation, and reparability. Prog Nucleic Acid Res Mol Biol. 1988; 35: 95-125.

5. Ohsawa I, Ishikawa M, Takahashi K, Watanabe M, Nishimaki K, Yamagata K, et al. Hydrogen acts as a therapeutic antioxidant by selectively reducing cytotoxic oxygen radicals. Nat Med. 2007; 13: 688-94. doi:nm1577 [pii]10.1038/nm1577.

6. Qian L, Mei K, Shen J, Cai J. Administration of hydrogen-rich saline protects mice from lethal acute graft-versus-host disease (aGVHD). Transplantation. 2013; 65: 658-62. doi:10.1097/TP.0b013e31827e6b2300007890-201303150-00003 [pii].

7. Qian L, Shen J. Hydrogen therapy may be an effective and specific novel treatment for Acute Graft-versus-host disease (GVHD). Journal of Cellular and Molecular Medicine. 2013; doi: 10.1111/jcmm.12081.

8. Qian L, Wu $\mathrm{Z}$, Shen J. Advances in the treatment of acute graft-versus-host disease. Journal of Cellular and Molecular Medicine. 2013; doi: 10.1111/jcmm.12093.

9. Nakao A, Toyoda Y, Sharma P, Evans M, Guthrie N. Effectiveness of hydrogen rich water on antioxidant status of subjects with potential metabolic syndrome-an open label pilot study. J Clin Biochem Nutr. 2010; 46: 140-9. doi:10.3164/jcbn.09-100.

10. Huang CS, Kawamura T, Toyoda Y, Nakao A. Recent advances in hydrogen research as a therapeutic medical gas. Free Radic Res. 2010; 44: 971-82. doi:10.3109/10715762.2010.500328.

11. Qian L, Li B, Cai J, Gao F. The hypothesis of an effective safe and novel radioprotective agent: hydrogen-rich solution. West Indian Med J. 2010; 59: $122-4$.

12. Qian L, Cao F, Cui J, Huang Y, Zhou X, Liu S, et al. Radioprotective effect of hydrogen in cultured cells and mice. Free Radic Res. 2010; 44: 275-82. doi:10.3109/10715760903468758.

13. Chuai Y, Shen J, Qian L, Wang Y, Huang Y, Gao F, et al. Hydrogen-rich saline protects spermatogenesis and hematopoiesis in irradiated BALB/c mice. Med Sci Monit. 2012; 18: BR89-94. doi:882513 [pii].

14. Chuai Y, Qian L, Sun X, Cai J. Molecular hydrogen and radiation protection. Free Radic Res. 2012; 46: 1061-7. doi:10.3109/10715762.2012.689429.

15. Chuai Y, Zhao L, Ni J, Sun D, Cui J, Li B, et al. A possible prevention strategy of radiation pneumonitis: combine radiotherapy with aerosol inhalation of hydrogen-rich solution. Med Sci Monit. 2011; 17: HY1-4. doi:881698 [pii].

16. Qian L, Cao F, Cui J, Wang Y, Huang Y, Chuai Y, et al. The potential cardioprotective effects of hydrogen in irradiated mice. J Radiat Res. 2010; 51: 741-7. doi:JST.JSTAGE/jrr/10093 [pii]. 
17. Liren Qian, Bailong Li, Fei Cao, Yuecheng Huang, Shulin Liu, Jianming Cai, et al. Hydrogen-rich PBS protects cultured human cells from ionizing radiation-induced cellular damage. Nuclear Technology and Radiation Protection. 2010; 25: 23-9.

18. Kang KM, Kang YN, Choi IB, Gu Y, Kawamura T, Toyoda Y, et al. Effects of drinking hydrogen-rich water on the quality of life of patients treated with radiotherapy for liver tumors. Med Gas Res. 2011; 1: 11. doi:2045-9912-1-11 [pii]10.1186/2045-9912-1-11.

19. Stadtman ER. Oxidation of free amino acids and amino acid residues in proteins by radiolysis and by metal-catalyzed reactions. Annu Rev Biochem. 1993; 62: 797-821. doi:10.1146/annurev.bi.62.070193.004053.

20. Fan X. Ionizing radiation induces formation of malondialdehyde, formaldehyde, and acetaldehyde from carbohydrates and organic acid. J Agric Food Chem. 2003; 51: 5946-9. doi:10.1021/jf0344340.

21. Kasai H. Analysis of a form of oxidative DNA damage, 8-hydroxy-2'-deoxyguanosine, as a marker of cellular oxidative stress during carcinogenesis. Mutat Res. 1997; 387: 147-63. doi:S1383-5742(97)00035-5 [pii].

22. Floyd RA. The role of 8-hydroxyguanine in carcinogenesis. Carcinogenesis. 1990; 11: 1447-50.

23. BN Pandey KM. Fluorescence and ESR studies on membrane oxidative damage by $\gamma$-radiation. Appl Magn Reson 2000; 18: 483-92.

24. Dubner D, Gisone P, Jaitovich I, Perez M. Free radicals production and estimation of oxidative stress related to gamma irradiation. Biol Trace Elem Res. 1995; 47: 265-70. doi:10.1007/BF02790126.

25. Verma SP, Sonwalkar N. Structural changes in plasma membranes prepared from irradiated Chinese hamster V79 cells as revealed by Raman spectroscopy. Radiat Res. 1991; 126: 27-35.

26. Giusti AM, Raimondi M, Ravagnan G, Sapora O, Parasassi T. Human cell membrane oxidative damage induced by single and fractionated doses of ionizing radiation: a fluorescence spectroscopy study. Int J Radiat Biol. 1998; 74: 595-605

27. Pohl LR. An immunochemical approach of identifying and characterizing protein targets of toxic reactive metabolites. Chem Res Toxicol. 1993; 6: 786-93.

28. Dixon BJ, Tang J, Zhang JH. The evolution of molecular hydrogen: a noteworthy potential therapy with clinical significance. Med Gas Res. 2013; 3: 10. doi:2045-9912-3-10 [pii]10.1186/2045-9912-3-10.

29. Pilcher JE. Senn on the Diagnosis of Gastro-Intestinal Perforation by the Rectal Insufflation of Hydrogen Gas. Ann Surg. 1888; 8: 190-204.

30. Dole M, Wilson FR, Fife WP. Hyperbaric hydrogen therapy: a possible treatment for cancer. Science. 1975; 190: 152-4.

31. Buxton GV GC, Helman WP, Ross AB. Critical review of rate constants for reactions of hydrated electrons, review of rate constants for reactions of hydrated electrons, hydrogen atoms and hydroxyl radicals in aqueous solution. J Phys Chem. 1988;: 513 - 886.

32. Gharib B, Hanna S, Abdallahi OM, Lepidi H, Gardette B, De Reggi M. Anti-inflammatory properties of molecular hydrogen: investigation on parasite-induced liver inflammation. C R Acad Sci III. 2001; 324: 719-24. doi:S0764446901013506 [pii].

33. Hayashida K, Sano M, Ohsawa I, Shinmura K, Tamaki K, Kimura K, et al. Inhalation of hydrogen gas reduces infarct size in the rat model of myocardial ischemia-reperfusion injury. Biochem Biophys Res Commun. 2008; 373: 30-5. doi:S0006-291X(08)01083-8 [pii]10.1016/j.bbrc.2008.05.165.

34. Buchholz BM, Kaczorowski DJ, Sugimoto R, Yang R, Wang Y, Billiar TR, et al. Hydrogen inhalation ameliorates oxidative stress in transplantation induced intestinal graft injury. Am J Transplant. 2008; 8: 2015-24. doi:AJT2359 [pii]10.1111/j.1600-6143.2008.02359.x.

35. Sun Q, Kang Z, Cai J, Liu W, Liu Y, Zhang JH, et al. Hydrogen-rich saline protects myocardium against ischemia/reperfusion injury in rats. Exp Biol Med (Maywood). 2009; 234: 1212-9. doi:0812-RM-349 [pii]10.3181/0812-RM-349.

36. Fukuda K, Asoh S, Ishikawa M, Yamamoto Y, Ohsawa I, Ohta S. Inhalation of hydrogen gas suppresses hepatic injury caused by ischemia/reperfusion through reducing oxidative stress. Biochem Biophys Res Commun. 2007; 361: 670-4. doi:S0006-291X(07)01552-5 [pii]10.1016/j.bbrc.2007.07.088.

37. Cai J, Kang Z, Liu WW, Luo X, Qiang S, Zhang JH, et al. Hydrogen therapy reduces apoptosis in neonatal hypoxia-ischemia rat model. Neurosci Lett. 2008; 441: 167-72. doi:S0304-3940(08)00732-5 [pii]10.1016/j.neulet.2008.05.077.

38. Fu Y, Ito M, Fujita Y, Ichihara M, Masuda A, Suzuki Y, et al. Molecular hydrogen is protective against 6-hydroxydopamine-induced nigrostriatal degeneration in a rat model of Parkinson's disease. Neurosci Lett. 2009; 453: 81-5. doi:S0304-3940(09)00183-9 [pii]10.1016/j.neulet.2009.02.016.

39. Nagata K, Nakashima-Kamimura N, Mikami T, Ohsawa I, Ohta S. Consumption of molecular hydrogen prevents the stress-induced impairments in hippocampus-dependent learning tasks during chronic physical restraint in mice. Neuropsychopharmacology. 2009; 34: 501-8. doi:npp200895 [pii]10.1038/npp.2008.95.

40. Mao YF, Zheng XF, Cai JM, You XM, Deng XM, Zhang JH, et al. Hydrogen-rich saline reduces lung injury induced by intestinal ischemia/reperfusion in rats. Biochem Biophys Res Commun. 2009; 381: 602-5. doi:S0006-291X(09)00376-3 [pii]10.1016/j.bbrc.2009.02.105.

41. Chuai Y, Gao F, Li B, Zhao L, Qian L, Cao F, et al. Hydrogen-rich saline attenuates radiation-induced male germ cell loss in mice through reducing hydroxyl radicals. Biochem J. 2012; 442: 49-56. doi:BJ20111786 [pii]10.1042/BJ20111786.

42. Saitoh Y, Harata Y, Mizuhashi F, Nakajima M, Miwa N. Biological safety of neutral-pH hydrogen-enriched electrolyzed water upon mutagenicity, genotoxicity and subchronic oral toxicity. Toxicol Ind Health. 2010; 26: 203-16. doi:0748233710362989 [pii]10.1177/0748233710362989.

43. Ramachandran A, Madesh M, Balasubramanian KA. Apoptosis in the intestinal epithelium: its relevance in normal and pathophysiological conditions. J Gastroenterol Hepatol. 2000; 15: 109-20.

44. Potten CS. Extreme sensitivity of some intestinal crypt cells to $X$ and gamma irradiation. Nature. 1977; 269: 518-21.

45. Grande T, Bueren JA. The mobilization of hematopoietic progenitors to peripheral blood is predictive of the hematopoietic syndrome after total or partial body irradiation of mice. Int J Radiat Oncol Biol Phys. 2006; 64: 612-8. doi:S0360-3016(05)02725-2 [pii]10.1016/j.ijrobp.2005.09.036.

46. Baranov A, Gale RP, Guskova A, Piatkin E, Selidovkin G, Muravyova L, et al. Bone marrow transplantation after the Chernobyl nuclear accident. N Engl J Med. 1989; 321: 205-12. doi:10.1056/NEJM198907273210401.

47. Normile D. Nuclear accident. Special treatment set for radiation victim. Science. 1999; 286: 207-9.

48. Yang Y, Gao F, Zhang H, Hunag Y, Zhang P, Liu C, et al. Molecular hydrogen protects human lymphocyte AHH-1 cells against $\mathrm{C}$ heavy ion radiation. Int J Radiat Biol. 2013; doi:10.3109/09553002.2013.817704.

49. Oakberg EF. Sensitivity and time of degeneration of spermatogenic cells irradiated in various stages of maturation in the mouse. Radiat Res. 1955; 2: 369-91.

50. Mauduit C, Siah A, Foch M, Chapet O, Clippe S, Gerard JP, et al. Differential expression of growth factors in irradiated mouse testes. Int J Radiat Oncol Biol Phys. 2001; 50: 203-12. doi:S0360-3016(01)01461-4 [pii].

51. Bruheim K, Svartberg J, Carlsen E, Dueland S, Haug E, Skovlund E, et al. Radiotherapy for rectal cancer is associated with reduced serum testosterone and increased FSH and LH. Int J Radiat Oncol Biol Phys. 2008; 70: 722-7. doi:S0360-3016(07)04462-8 [pii]10.1016/j.ijrobp.2007.10.043.

52. Samarth RM, Samarth M. Protection against radiation-induced testicular damage in Swiss albino mice by Mentha piperita (Linn.). Basic Clin Pharmacol Toxicol. 2009; 104: 329-34. doi:PTO384 [pii]10.1111/j.1742-7843.2009.00384.x.

53. Meistrich ML, Finch MV, Hunter N, Milas L. Cytotoxic effects of WR-2721 on mouse testicular cells. Int J Radiat Oncol Biol Phys. 1984; 10: 1551-4. doi:0360-3016(84)90501-7 [pii]

54. Costabile RA. The effects of cancer and cancer therapy on male reproductive function. J Urol. 1993; 149: 1327-30.

55. Gosselin TK, Mautner B. Amifostine as a radioprotectant. Clin J Oncol Nurs. 2002; 6: 175-6, 80. doi:10.1188/02.CJON.175-176.

56. Jiang Z, Xu B, Yang M, Li Z, Zhang Y, Jiang D. Protection by hydrogen against gamma ray-induced testicular damage in rats. Basic Clin Pharmacol Toxicol. 2013; 112: 186-91. doi:10.1111/bcpt.12016.

57. Mei K, Zhao S, Qian L, Li B, Ni J, Cai J. Hydrogen protects rats from dermatitis caused by local radiation. J Dermatolog Treat. 2013; doi:10.3109/09546634.2012.762639.

58. Murphy BA, Gilbert J. Dysphagia in head and neck cancer patients treated with radiation: assessment, sequelae, and rehabilitation. Semin Radiat Oncol. 2009; 19: 35-42. doi:S1053-4296(08)00062-3 [pii]10.1016/j.semradonc.2008.09.007.

59. Hymes SR, Strom EA, Fife C. Radiation dermatitis: clinical presentation, pathophysiology, and treatment 2006. J Am Acad Dermatol. 2006; 54: 28-46. doi:S0190-9622(05)02707-6 [pii]10.1016/j.jaad.2005.08.054.

60. Guo Z, Zhou B, Li W, Sun X, Luo D. Hydrogen-rich saline protects against ultraviolet $B$ radiation injury in rats. J Biomed Res. 2012; 26: 365-71. doi:10.7555/JBR.26.20110037jbr-26-05-365 [pii].

61. Ignacio RM, Yoon Y-S, Sajo MEJ, Kim C-S, Kim D-H, Kim S-K, et al. The balneotherapy effect of hydrogen reduced water on UVB-mediated skin injury in hairless mice. Molecular \& Cellular Toxicology. 2013; 9: 15-21.

62. Shin MH, Park R, Nojima H, Kim HC, Kim YK, Chung JH. Atomic hydrogen surrounded by water molecules, $\mathrm{H}(\mathrm{H} 2 \mathrm{O}) \mathrm{m}$, modulates basal and UV-induced gene expressions in human skin in vivo. PLoS One. 2013; 8: e61696. doi:10.1371/journal.pone.0061696PONE-D-12-32948 [pii]. 
63. Para AE, Bezjak A, Yeung IW, Van Dyk J, Hill RP. Effects of genistein following fractionated lung irradiation in mice. Radiother Oncol. 2009; 92: 500-10. doi:S0167-8140(09)00162-5 [pii]10.1016/j.radonc.2009.04.005.

64. Deeg HJ. Acute and delayed toxicities of total body irradiation. Seattle Marrow Transplant Team. Int J Radiat Oncol Biol Phys. 1983; 9: 1933-9. doi:0360-3016(83)90365-6 [pii].

65. Beyzadeoglu M, Oysul K, Dirican B, Arpaci F, Balkan A, Surenkok S, et al. Effect of dose-rate and lung dose in total body irradiation on interstitial pneumonitis after bone marrow transplantation. Tohoku J Exp Med. 2004; 202: 255-63.

66. Sampath S, Schultheiss TE, Wong J. Dose response and factors related to interstitial pneumonitis after bone marrow transplant. Int J Radiat Oncol Biol Phys. 2005; 63: 876-84. doi:S0360-3016(05)00395-0 [pii]10.1016/j.jijrobp.2005.02.032.

67. Terasaki Y, Ohsawa I, Terasaki M, Takahashi M, Kunugi S, Dedong K, et al. Hydrogen therapy attenuates irradiation-induced lung damage by reducing oxidative stress. Am J Physiol Lung Cell Mol Physiol. 2011; 301: L415-26. doi:ajplung.00008.2011 [pii]10.1152/ajplung.00008.2011.

68. Lee CK, Aeppli D, Nierengarten ME. The need for long-term surveillance for patients treated with curative radiotherapy for Hodgkin's disease: University of Minnesota experience. Int J Radiat Oncol Biol Phys. 2000; 48: 169-79. doi:S0360-3016(00)00647-7 [pii].

69. Lauk S. Endothelial alkaline phosphatase activity loss as an early stage in the development of radiation-induced heart disease in rats. Radiat Res. 1987; 110: 118-28.

70. Lauk S, Kiszel Z, Buschmann J, Trott KR. Radiation-induced heart disease in rats. Int J Radiat Oncol Biol Phys. 1985; 11: 801-8. doi:0360-3016(85)90314-1 [pii].

71. Stewart JR, Fajardo LF, Gillette SM, Constine LS. Radiation injury to the heart. Int J Radiat Oncol Biol Phys. 1995; 31: 1205-11. doi:0360-3016(94)00656-6 [pii]10.1016/0360-3016(94)00656-6.

72. Huo H-m, Yang S, Chen L-s, Lu H-j, Wang A-d, Zhang L-y. Hydrogen-rich saline alleviation on the oxidative stress and early-phase radiation-induced brain injury in rats. Chinese Journal of Radiological Medicine and Protection. 2012; 32: 485-7.

73. Little JB. Radiation carcinogenesis. Carcinogenesis. 2000; 21: 397-404.

74. Potworowski EF, Gagnon F, Beauchemin C, St Pierre Y. Dendritic cells prevent radiation-induced thymic lymphoma. Leukemia. 1996; 10: $1639-47$.

75. Shin SC, Kang YM, Kim HS. Life span and thymic lymphoma incidence in high- and low-dose-rate irradiated AKR/J mice and commonly expressed genes. Radiat Res.2010; 174: 341-6. doi:10.1667/RR1946.1.

76. Zhao L, Zhou C, Zhang J, Gao F, Li B, Chuai Y, et al. Hydrogen protects mice from radiation induced thymic lymphoma in BALB/c mice. Int J Biol Sci. 2011; 7: 297-300.

77. Schoenfeld MP, Ansari RR, Zakrajsek JF, Billiar TR, Toyoda Y, Wink DA, et al. Hydrogen therapy may reduce the risks related to radiation-induced oxidative stress in space flight. Med Hypotheses. 2010; $\quad 76: \quad 117-8 . \quad$ doi:S0306-9877(10)00350-6 [pii]10.1016/j.mehy.2010.08.046.

78. Itoh T, Fujita $\mathrm{Y}$, Ito M, Masuda A, Ohno K, Ichihara M, et al. Molecular hydrogen suppresses FcepsilonRI-mediated signal transduction and prevents degranulation of mast cells. Biochem Biophys Res Commun. 2009; 389: 651-6. doi:S0006-291X(09)01849-X [pii]10.1016/j.bbrc.2009.09.047.

79. Itoh $T$, Hamada $N$, Terazawa $R$, Ito $M$, Ohno $K$, Ichihara $M$, et al. Molecular hydrogen inhibits lipopolysaccharide/interferon gamma-induced nitric oxide production through modulation of signal transduction in macrophages. Biochem Biophys Res Commun. 2011; 411: 143-9. doi:S0006-291X(11)01096-5 [pii]10.1016/j.bbrc.2011.06.116.

80. Nakai $Y$, Sato B, Ushiama S, Okada S, Abe $K$, Arai S. Hepatic oxidoreduction-related genes are upregulated by administration of hydrogen-saturated drinking water. Biosci Biotechnol Biochem. 2011; 75: 774-6. doi:JST.JSTAGE/bbb/100819 [pii].

81. Genvresse I, Lange C, Schanz J, Schweigert M, Harder H, Possinger K, et al. Tolerability of the cytoprotective agent amifostine in elderly patients receiving chemotherapy: a comparative study. Anticancer Drugs. 2001; 12: $345-9$. 